\title{
LAS LICENCIAS OBLIGATORIAS SOBRE PATENTES EN EL MARCO NORMATIVO COLOMBIANO*
}

Compulsory Licenses about Patents in the Colombian Legal Framework*

\section{Cristian David Jurado Ferrer*}

Fecha de Recepción: Mayo 6 de 2013

Fecha de Aceptación: Mayo 13 de 2013

SUMARIO: 1. Introducción; 2. Marco normativo de la propiedad en general y la industrial en particular dentro del derecho colombiano; 3. De las licencias obligatorias; 4. Viabilidad de otorgamiento de licencias obligatorias; 5 . Conclusiones; 6 . Referencias bibliográficas.

\footnotetext{
"Articulo de Investigación realizado en medio de los estudios de la Maestría en Derecho privado de la Universidad del Rosario.

" Abogado egresado de la Universidad de Cartagena. Especialista en Derecho Comercial de la Universidad Libre, sede Cartagena. Candidato a Magíster de la Maestría en Derecho Privado de la Universidad Nacional de Rosario (Argentina). Correo electrónico: cristian_jurado_ferrer@hotmail.com. Centro, edificio Bancafé, oficina 301. Cartagena,Colombia.
} 


\section{COMO CITAR ESTE ARTÍCULO (APA 6th)}

Jurado Ferrer, C. D. (2013) Las licencias obligatorias sobre patentes en el marco normativo colombiano. (Y. Carrillo De la rosa, Ed.) Revista Mario Alario D'filippo V(10), págs. 25-41

\section{RESUMEN}

La propiedad es un derecho fundamental consagrado en la Constitución Nacional. Pero su ejercicio implica obligaciones y debe estar acorde al interés general, dada la función social que le es inherente. La propiedad industrial no escapa de estas directrices, por lo que al ser concedida una patente, muy a pesar del carácter monopólico y exclusivo que envuelve, puede ser limitada a través de lo que se conoce como "licencias obligatorias". Estas figuras permiten la explotación del derecho por un tercero, en las situaciones y mediante los requisitos que el marco normativo colombiano impone.

\section{PALABRAS CLAVE}

Propiedad; patentes; licencias obligatorias.

\section{ABSTRACT}

The property is a fundamental right enshrined in the Constitution. But his exercise involves obligations and must be consistent with the general interest, given the social function that is inherent. Industrial property does not escape these guidelines, so to be granted a patent, in spite of monopoly and exclusive wrapping, it can be limited by what is known as "compulsory licenses". These figures allow the exploitation of rights by a third party in situations and by the requirements imposed by the Colombian regulatory framework.

\section{KEYWORDS}

Property; patents; compulsory licenses. 


\section{INTRODUCCIÓN}

Las licencias obligatorias constituyen sin duda uno de los temas más interesantes dentro de la propiedad industrial en general. De hecho, es una medida que permite mediar entre la tensión del monopolio que las patentes otorga a su titular y la proyección con el interés general que deben cumplir este tipo de bienes, que a la postre conforme la Constitución Política de Colombia, se garantiza la propiedad privada, no sin precisar que debe cumplir una función social y que implica obligaciones ${ }^{1}$.

Si bien su aplicación y popularidad dista mucho de las necesidades sociales que a nivel mundial se presentan por el gran número de enfermedades que agobian a la humanidad, en contraste con el alto precio de los medicamentos que permiten combatir problemas de salud de alto impacto, al menos, resulta una figura jurídica útil para contrarrestar la problemática que en términos económicos representa para los sectores vulnerables el acceder a medicamentos patentados que resultan ser el único camino para enfrentar dignamente estos males.

Por ello, nos hemos querido referir a esta figura que opera dentro del tema de las Patentes de Invención, propiedad industrial que por excelencia es vista como uno de los negocios más solventes, pero que sin duda requiere la mayor inversión para lograr sus objetivos y su desarrollo, lo que conduce a que genere opiniones, y por qué no, sentimientos encontrados en cuanto al tema.

No obstante, no abordaremos el carácter económico o su problemática para las farmacéuticas, sino lo que toca con las hipótesis existentes para el próspero otorgamiento de las licencias obligatorias de cara al la normatividad existente, que no se reducen únicamente a las licencias por razones de interés público, de emergencia o de seguridad nacional (siendo los casos sensibles para los titulares de patentes de medicamentos y los enfermos), pues son varios los supuestos para que operen las licencias obligatorias.

Nos limitaremos entonces a precisar dentro de la óptica del ordenamiento jurídico colombiano, las hipótesis, cuál es el marco normativo aplicable a esta figura, definir la misma y precisar sus límites y órgano competente para conocer de ellas, refiriéndonos posteriormente a los eventos particulares previstos como procedentes para otorgarlas y los requisitos y trámite a adelantar.

\footnotetext{
${ }^{1}$ Se garantizan la propiedad privada y los demás derechos adquiridos con arreglo a las leyes civiles, los cuales no pueden ser desconocidos ni vulnerados por leyes posteriores. Cuando de la aplicación de una ley expedida por motivos de utilidad pública o interés social, resultare en conflicto los derechos de los particulares con la necesidad por ella reconocida, el interés privado deberá ceder al interés público o social.

La propiedad es una función social que implica obligaciones. Como tal, le es inherente una función ecológica.

El Estado protegerá y promoverá las formas asociativas y solidarias de propiedad.

Por motivos de utilidad pública o interés social definidos por el legislador, podrá haber expropiación mediante sentencia judicial e indemnización previa. Este se fijará consultando los intereses de la comunidad y del afectado. En los casos que determine el legislador, dicha expropiación podrá adelantarse por vía administrativa, sujeta a posterior acción contenciosa-administrativa, incluso respecto del precio.
} 


\section{MARCO NORMATIVO DE LA PROPIEDAD EN GENERAL Y LA INDUSTRIAL EN PARTICULAR DENTRO DEL DERECHO COLOMBIANO}

Primeramente, es de considerar que para la ubicación de lo relativo a las Patentes y la Propiedad Industrial en general, es necesario referirse al marco constitucional que en el derecho colombiano regula la propiedad y la libertad de empresa. La primera, por cuanto se encuentran estos bienes mercantiles inmersos dentro del derecho de propiedad. La segunda, por cuanto los titulares de los derechos que las patentes conceden, se encuentran amparados por esta libertad de raigambre constitucional.

Esto por cuanto como se anotó, ambas situaciones sustentan la procedencia del carácter fundamental de la propiedad en sentido general, y la industrial en particular, por lo que son bases constitucionales para otorgar patentes de invención, pero también para darle viabilidad a las licencias obligatorias de las mismas.

La propiedad industrial es un bien reconocido por el derecho colombiano. Es así como el título II del libro tercero del Código de Comercio (Colombia, 1971), que consagra lo relativo a los bienes mercantiles, regulaba lo atinente a aquellas.

Decimos regulaba, porque las normas que se referían a las mismas han tenido constantes modificaciones por parte de disposiciones comunitarias, rigiendo en la actualidad la Decisión 486 del 2000 del Acuerdo de Cartagena ${ }^{2}$, dentro del marco de la Comunidad Andina de Naciones. (Comunidad Andina de Naciones, 2000)

En este orden de ideas, como es natural, se entiende a esta clase de bienes dentro de la órbita del derecho de propiedad, que es protegido, como se anotó en líneas anteriores, por la Constitución Nacional (Asamblea Nacional Constituyente, 1991) en su Artículo 58, pero no de manera absoluta sino fijándole una función social.

Pero más allá de la función social que sobre el derecho a la propiedad impone la Carta Magna (Asamblea Nacional Constituyente, 1991), otros principios y derechos se derivan del mismo texto, por ejemplo, vemos como se protege en nuestro ordenamiento la libertad para la consecución del conocimiento y la expresión artística, señalando que el Estado creará incentivos para personas e instituciones que desarrollen y fomenten la ciencia y la tecnología y las demás manifestaciones culturales y ofrecerá estímulos especiales a personas e instituciones que ejerzan estas actividades ${ }^{3}$.

Esto guarda consonancia con las libertades consagradas en las normas superiores, máxime si es

\footnotetext{
${ }^{2}$ El Título Segundo del Libro Tercero del Código de Comercio colombiano, relativo a la propiedad industrial, fue modificado por la Decisión 85 del Acuerdo de Cartagena incorporada a la legislación nacional por medio del Decreto 1190 de 1978. A su vez, la citada Decisión fue modificada por la Decisión 313 del 6 de febrero de 1992, la cual estableció un régimen común sobre propiedad industrial, reglamentado parcialmente por el Decreto 575 de 1992. La Decisión 313 fue sustituida por la Decisión 344 del 21 de octubre de 1993 del Acuerdo de Cartagena. La Decisión 344 fue reglamentada mediante el Decreto 117 de 1994. Y esta última Decisión fue sustituida por la 486 de 2000.

3 Artículo 71 ibídem.
} 
protegida la propiedad privada y se le atribuye una connotación de derecho fundamental, con las implicaciones que esto trae para su protección y ejercicio. Sumado a ello, vemos que la libertad de empresa se perfila en la Constitución actual de 1991, como un estandarte para la consecución de los propósitos del Estado y creación de riquezas, pero al igual que la propiedad, se le atribuye un carácter que debe mirar a la función e interés social que de ella se desprende. Es así como el Artículo 333 de la Constitución Política lo expresa:

ARTícULO 333. La actividad económica y la iniciativa privada son libres, dentro de los límites del bien común. Para su ejercicio, nadie podrá exigir permisos previos ni requisitos, sin autorización de la ley.

La libre competencia económica es un derecho de todos que supone responsabilidades.

La empresa, como base del desarrollo, tiene una función social que implica obligaciones. El Estado fortalecerá las organizaciones solidarias y estimulará el desarrollo empresarial.

El Estado, por mandato de la ley, impedirá que se obstruya o se restrinja la libertad económica y evitará o controlará cualquier abuso que personas o empresas hagan de su posición dominante en el mercado nacional.

La ley delimitará el alcance de la libertad económica cuando así lo exijan el interés social, el ambiente y el patrimonio cultural de la Nación.

Esto a su vez, viene de la mano con las prescripciones que el Artículo 334 del mismo cuerpo normativo cuando establece que: [L]a dirección general de la economía estará a cargo del Estado. Este intervendrá, por mandato de la ley, en la explotación de los recursos naturales, en el uso del suelo, en la producción, distribución, utilización y consumo de los bienes, y en los servicios públicos y privados, para racionalizar la economía con el fin de conseguir en el plano nacional y territorial, en un marco de sostenibilidad fiscal, el mejoramiento de la calidad de vida de los habitantes, la distribución equitativa de las oportunidades y los beneficios del desarrollo y la preservación de un ambiente sano.

Aparte de la Constitución, en el plano nacional, la propiedad industrial es regulada por varias disposiciones, entre las cuales vale la pena resaltar la Ley 463 de 1998, por medio de la cual se aprueba el "Tratado de cooperación en materia de patentes (PCT)", elaborado en Washington el 19 de junio de 1970, enmendado el 28 de septiembre de 1979 y modificado el 3 de febrero de 1984, y el reglamento del tratado de cooperación en materia de patentes. Ley 178 de 1994, Por medio de la cual se aprueba el "Convenio de París para la Protección de la Propiedad Industrial", hecho en París el 20 de marzo de 1883, revisado en Bruselas el 14 de diciembre de 1900, en Washington el 2 de junio de 1911, en la Haya el 6 de noviembre de 1925, en Londres el 2 de junio de 1934, en Lisboa el 31 de octubre de 1958, en Estocolmo el 14 de julio de 1967 y enmendado el 2 de octubre de 1979. Ley 46 de 1979, por medio de la cual se autoriza al Gobierno Nacional para suscribir la adhesión de Colombia "al Convenio que establece la Organización Mundial de la Propiedad Intelectual", firmado en Estocolmo el 14 de julio de 1967. Decreto 427 de 2001. Por el cual se promulga el "Tratado de Cooperación en Materia de Patentes (PCT)" elaborado en Washington el 19 de junio de 1970, 
enmendado el 28 de septiembre de 1979 y modificado el 3 de febrero de 1984 y el Reglamento del Tratado de Cooperación en Materia de Patentes. (Decreto 2591 de 2000, por el cual se reglamenta parcialmente la Decisión 486 de la Comisión de la Comunidad Andina.

En cuanto al recorrido en los tratados internacionales, vale mencionar el Acuerdo por el que se establece la Organización Mundial del Comercio (OMC), 1994 (Comité de Negociaciones Comerciales, 1994). Anexo $1 \mathrm{C}$ - Acuerdo sobre los aspectos de los derechos de propiedad intelectual relacionados con el comercio (ADPIC) (Comité de Negociaciones Comerciales, 1994); Convenio que establece la Organización Mundial de la Propiedad Intelectual de 1979, entre otros.

Sentado el marco normativo anterior, corresponde situar el tema de la propiedad industrial dentro del derecho mercantil colombiano, el cual está regido al día de hoy, como se ha anotado, por la Decisión 486 del 2000 del Acuerdo de Cartagena (Comunidad Andina de Naciones, 2000), que actúa como norma supranacional, que reiteramos sustituyó la Decisión 344 de la Comunidad Andina de Naciones ${ }^{4}$.

La Comunidad Andina de Naciones (CAN), fue creada mediante el Acuerdo de Cartagena, firmado en Cartagena de Indias (Colombia) el 26 de mayo de 1969. En la actualidad fungen como países miembros Bolivia, Ecuador, Perú y por supuesto, Colombia.

Dentro de esta comunidad de integración, existe la denominada "Comisión de la Comunidad Andina", el cual cumple el papel de órgano normativo del Sistema Andino de Integración, compuesto por un representante plenipotenciario de cada un de los Países Miembros, cuya capacidad legislativa, expresada en la adopción de Decisiones, la comparte ahora con el Consejo Andino de Ministros de Relaciones Exteriores.

Es en virtud de lo anterior que la temática referente a la propiedad industrial en Colombia se rige por la Decisión 486 de la Comisión de la Comunidad Andina, del 14 de septiembre de 2000.

Vale la pena resaltar las disposiciones que guardan relación con el tema propuesto abordar en el presente ensayo, en lo que resumiremos señalando que el Capítulo I de esta Decisión establece los requisitos de patentabilidad, donde preceptúa: Artículo 14.- Los Países Miembros otorgarán patentes para las invenciones, sean de producto o de procedimiento, en todos los campos de la tecnología, siempre que sean nuevas, tengan nivel inventivo y sean susceptibles de aplicación industrial. Renglón seguido, se desarrolla lo que a estos requisitos refiere, sobre qué no es considerado invención, cuándo existe novedad, aplicación industrial y nivel inventivo, así como la patentabilidad o no de ciertas invenciones ${ }^{5}$.

\footnotetext{
${ }^{4}$ Pero junto a la Decisión 486, la propiedad industrial en el derecho colombiano se encuentra regulada por normas supranacionales como la Decisión 391 de 1996 del Régimen Común sobre Acceso a los Recursos Genéticos; Decisión 291 de 1991 relativa al Régimen Común de Tratamiento a los Capitales Extranjeros y sobre Marcas, Patentes, Licencias y Regalías; Clasificación de Niza, octava edición, 2002 contenida en el Arreglo de Niza 84; Clasificación internacional de patentes, sexta edición, 1994, contenida en el Arreglo de Estrasburgo de 1971; Clasificación internacional para los dibujos y modelos industriales, 1968, modificado en 1979, contenida en el Arreglo de Locarno; Clasificación internacional de elementos figurativos de las marcas contenida en el Arreglo de Viena. Estas señaladas para presentar una ubicación global de las normas de carácter no nacional

${ }^{5}$ Artículos 15 a 21.
} 
El derecho que otorgan las invenciones, es decir, la patente, corresponde al inventor, que siendo varios corresponderá en común a todos. En todo caso, según lo normado por el Artículo 22, el derecho podrá ser transferido por acto entre vivos o por vía sucesoria, en armonía con el 56 ibídem. Sin perjuicio de lo relativo a las invenciones ocurridas bajo relaciones laborales y la cesión de los beneficios económicos en estos $\operatorname{casos}^{6}$.

Dentro de los derechos establecidos por la patente como es sensato, confiere a su titular el monopolio acolitado expresamente por la ley, que genera un derecho exclusividad que se traduce además, en impedir a terceras personas que no tengan su consentimiento, realizar cualquiera de los siguientes actos:

a) Cuando en la patente se reivindica un producto:

i) fabricar el producto;

ii) ofrecer en venta, vender o usar el producto; o importarlo para alguno de estos fines; $y$,

b) Cuando en la patente se reivindica un procedimiento:

i) emplear el procedimiento; o

ii) ejecutar cualquiera de los actos indicados en el literal a) respecto a un producto obtenido directamente mediante el procedimiento.

Artículo 53.- El titular de la patente no podrá ejercer el derecho a que se refiere el artículo anterior respecto de los siguientes actos:

a) actos realizados en el ámbito privado y con fines no comerciales;

b) actos realizados exclusivamente con fines de experimentación, respecto al objeto de la invención patentada;

c) actos realizados exclusivamente con fines de enseñanza o de investigación científica o académica;

d) actos referidos en el Artículo 5 del Convenio de París para la Protección de la Propiedad Industrial;

e) cuando la patente proteja un material biológico excepto plantas, capaz de reproducirse, usarlo como base inicial para obtener un nuevo material viable, salvo que tal obtención requiera el uso repetido de la entidad patentada ${ }^{7}$.

\footnotetext{
${ }^{6}$ Artículo 23.- Sin perjuicio de lo establecido en la legislación nacional de cada País Miembro, en las invenciones ocurridas bajo relación laboral, el empleador, cualquiera que sea su forma y naturaleza, podrá ceder parte de los beneficios económicos de las invenciones en beneficio de los empleados inventores, para estimular la actividad de investigación.

Las entidades que reciban financiamiento estatal para sus investigaciones deberán reinvertir parte de las regalías que reciben por la comercialización de tales invenciones, con el propósito de generar fondos continuos de investigación y estimular a los investigadores, haciéndolos partícipes de los rendimientos de las innovaciones, de acuerdo con la legislación de cada País Miembro.

${ }^{7}$ Artículo 53
} 
No obstante, no otorga derecho para impedir a un tercero realizar actos de comercio respecto de un producto protegido por la patente, después de haber sido introducido en el comercio por el titular de la patente u otra persona con su consentimiento o vinculación económica, bajo el tenor del Artículo 54, por el denominado "agotamiento del derecho".

Ahora bien, como se ha dicho, la patente es un derecho del titular que puede ser transferida por actos entre vivos, a través de lo que se denominan "licencias".

Estas, son producto de la autonomía de la voluntad del titular del derecho, quien celebra el negocio jurídico respectivo con el tercero para que explote la invención, registrándose en la autoridad nacional competente, que en el caso de Colombia lo es la Superintendencia de Industria y Comercio (SIC), conocida también como Superindustria ${ }^{8}$.

Es potestativo del titular hacer los que a bien tenga con su patente, por lo que su voluntad podrá desplegarla para efectos de conceder licencia a uno o varios terceros, libremente.

Situación diversa se presenta cuando se trata de las licencias que obligatoriamente se conceden por parte de las autoridades nacionales, que resulta el tema del presente trabajo.

Si bien la propiedad industrial traducida en las patentes otorga unas prerrogativas y constituye un bien en cabeza del titular, como se anotó al inicio del presente trabajo, el derecho de propiedad debe tener una función social y velar en lo posible por el interés general. Esto tiene consonancia con las patentes, pues el titular adquiere obligaciones, en las que hay que destacar la relativa a la explotación de la invención, la desatención de esta obligación habilita una de las hipótesis para la solicitud de licencias por parte de terceros, como se pasará a explicar luego de transcribir los artículos 59 y 60, que resultan de vital interés para el desarrollo del tema.

Artículo 59.- El titular de la patente está obligado a explotar la invención patentada en cualquier País Miembro, directamente o a través de alguna persona autorizada por él.

Artículo 60.- A los efectos del presente Capítulo, se entenderá por explotación, la producción industrial del producto objeto de la patente o el uso integral del procedimiento patentado junto con la distribución y comercialización de los resultados obtenidos, de forma suficiente para satisfacer la demanda del mercado. También se entenderá por explotación la importación, junto con la distribución y comercialización del producto patentado, cuando esta se haga de forma suficiente para satisfacer la demanda del mercado. Cuando la patente haga referencia a un procedimiento que no se materialice en un producto, no serán exigibles los requisitos de comercialización y distribución.

\footnotetext{
${ }^{8}$ Superindustria en el sentido de que es una Superintendencia, particularmente la de Industria y Comercio, siendo la de Sociedades conocida como Supersociedades; la Financiera, Superfinanciera; y así.

Es de mencionar que La Superintendencia de Industria y Comercio es un organismo administrativo (con delegación de facultades jurisdiccionales en algunos asuntos) de carácter técnico, adscrito al Ministerio de Comercio Industria y Turismo, creada mediante decreto 623 de 1974 y marco de modernización del Estado, le fueron suprimidas unas funciones y fortalecidas otras, subsistiendo las relacionadas con la propiedad intelectual.
} 


\section{DEBERES DE LA SOCIEDAD INSCRITA: DIMENSIÓN NORMATIVA}

Antes de abordar las clases de Licencias Obligatorias sobre patentes, las condiciones y requisitos de otorgamiento conforme el marco ADPIC, la Decisión 486 de la Comisión de la Comunidad Andina y la Declaración del 30 de agosto de 2003 del Consejo General de la OMC; todas estas imperantes dentro del régimen colombiano, es importante precisar en qué consisten estas. Salamolard (como se citó en Correa \& Bergel, 1996) afirma:

"[Es] un elemento orgánico en el sistema de patentes, cuya función es la de garantizar la realización de los objetivos propios de este sistema. Conforme a esta posición se define, la licencia obligatoria como una medida orgánica positiva en el sistema de patentes tendiente a provocar que no surja una distorsión entre el interés público y el interés particular del patentado. No se trata de una excepción. Sino de un elemento regular que integra y delimita el derecho de patentes".

Podemos decir que es una figura jurídica en la que habiendo sido concedida previamente por un Estado una patente, permite que el Estado mismo o un particular, produzcan el producto o utilice el procedimiento patentado, sin el consentimiento de su titular, teniendo en cuenta algunas condiciones y requisitos.

Se plasman las licencias obligatorias como un mecanismo apto para equilibrar los posibles efectos negativos que genera un monopolio autorizado como el que resulta del otorgamiento de una patente frente al interés público, sobretodo en el sector farmacéutico. Sin embargo esta medida es fuertemente criticada por su poca utilización y timidez con que los gobiernos la contemplan, aunque en los últimos años algunos países hayan decidido otorgarlas, muy a pesar de los argumentos presentados por las industrias farmacéuticas especialmente acerca de las grandes pérdidas que estas medidas le generan y el aspecto perjudicial que conlleva al desestimular y dificultar las investigaciones e inversión para nuevos medicamentos.

Sin embargo, se dice que la importancia y virtud de esta figura no radica en el número de licencias que se otorguen, sino en que al ser consagradas normativamente, permiten que los titulares puedan bajar los precios de los productos y que se den licencias voluntarias en términos más razonables.

Pero como recurso para hacer primar y proteger el interés general frente al particular, las licencias obligatorias para poder ser otorgadas, se deben cumplir algunas condiciones y llenar los requisitos establecidos.

En todo caso la concesión de las licencias obligatorias no priva al titular de recibir remuneración por ellas, ni de explotar su invento o procedimiento patentado.

\section{SOCIEDAD INSCRITA Y EMISOR DE VALORES}

Anotado lo anterior, procederemos a señalar las hipótesis que dan lugar al otorgamiento de estas licencias obligatorias y las condiciones y requisitos necesarios para su viabilidad, individualmente 
consideradas. Esto desde la óptica del ordenamiento que rige para el derecho colombiano, primero en cuanto a los aspectos de fondo y luego los aspectos formales y procedimentales ante el órgano competente.

\section{a) LICENCIA POR FALTA DE EXPLOTACIÓN DE PARTE DE SU TITULAR}

Siendo que es una obligación del titular de la patente explotar la invención patentada, ya sea directamente o a través de alguna persona autorizada por este, mediante la producción y comercialización, o la importación y comercialización, tal y como se desprende de los artículos 59 y 60 de la Decisión 486 de la Comunidad Andina de Naciones; es lógico que el incumplimiento injustificado por parte de su titular, genere consecuencias en cuanto a la utilización de la patente por personas distintas, quienes deseen explotar la invención patentada.

Conforme el artículo 61 de la Decisión 486 (Comunidad Andina de Naciones, 2000), el otorgamiento de la licencia obligatoria corresponde a la autoridad competente, en nuestro caso la Superintendencia de Industria y Comercio, previa solicitud de cualquier interesado. Esa solicitud debe, en cuanto a forma, adecuarse a lo establecido por la Circular Única Superindustria (Circular Externa 10/2001) y a la Resolución 12 del 7 de enero de 2010.

En cuanto a los aspectos de fondo, o sus requisitos para ser concedida se debe tener en cuenta:

1. Que al momento de la solicitud la patente no se hubiere explotado como lo indican los Artículos 59 y 60 de la Decisión; o hubiese estado suspendida por más de un año.

2. El plazo se contabiliza de dos maneras: Tres años contados a partir de la concesión de la patente, o cuatro contados a partir de la solicitud de la misma. Pero en todo caso, el que resulte más extendido.

No quiere decir que se pueda otorgar licencia obligatoria para inventos cuya patente solo está en curso (tanto para licencias por falta de explotación como para las demás), sino para patentes ya concedidas, pues lo que indica es que se verificar el término de la solicitud o el de la concesión, atendiendo al que sea mayor ${ }^{9}$.

3. Es necesario que el solicitante hubiese intentado previamente obtener una licencia contractual por parte de titular de la patente.

4. Que el acercamiento previo para la obtención de licencia contractual haya sido solicitado en términos y condiciones comerciales razonables, y no haya tenido efecto en un plazo prudencial.

Este requisito debe ser valorado por la Superintendencia de Industria y Comercio, especialmente en cuanto a que los términos y condiciones comerciales sean razonables, y que el plazo haya sido prudencial, pues la normatividad nada dice qué debe entenderse por razonable o prudencial, pero

${ }^{9}$ En este sentido: Superintendencia de Industria y Comercio, Concepto 060113430 del 10 de diciembre de 2006 
siendo la Superintendencia la autoridad a quien corresponde otorgar la licencia obligatoria cuando se cumplan las exigencias, le corresponde la interpretación que considere ajustada a estos parámetros.

5. No debe existir excusa legítima que justifique la inacción del titular de la patente, entre las cuales se encuentran la fuerza mayor y el caso fortuito.

En cuanto al término, objeto, alcance, condiciones y monto de la compensación económica, debe ser establecida por la autoridad competente.

La compensación debe ser adecuada, teniendo en cuenta las condiciones de cada caso y considerando en especial el valor económico de la autorización ${ }^{10}$. Asimismo el literal f) del Artículo 68 de la Decisión 486 reitera el punto sobre tener en cuenta las circunstancias concretas y el valor económico para determinar la remuneración.

Tratándose del alcance y duración de la licencia el mencionado Artículo 68 en su literal d) indica que éstas se limitarán en función de los fines que fueron propuestos, al igual que el literal c) del artículo 31 de la ADPIC.

Las condiciones de las licencias otorgadas pueden ser modificadas por la oficina nacional competente, a solicitud del titular de la patente o del licenciatario, cuando así lo justifiquen nuevos hechos y cuando el titular de la patente conceda otra licencia en condiciones más favorables ${ }^{11}$.

Dado que la finalidad de la licencia por no explotación es que esta se dé, el licenciatario estará obligado a explorar la invención dentro del plazo de dos años desde el momento en que le concedan la licencia. Y solo es excusable que alegue su no explotación por fuerza mayor o caso fortuito ${ }^{12}$, más no otra causa que lo justifique.

De no ser explotada la invención, se revocará la licencia obligatoria. En lo tocante al procedimiento previsto por el órgano competente, resumimos el mismo resaltando que:

पLa solicitud de licencia deberá cumplir con los requisitos del Art. 5 del Código Contencioso Administrativo (Colombia, 1984) ${ }^{13}$.

\ La SIC examinará, dentro de los quince (15) días hábiles siguientes, contados a partir de la fecha de presentación de la solicitud, si la misma cumple con los requisitos dispuestos.

\footnotetext{
${ }^{10}$ Inciso segundo del artículo 62 de la Decisión 486 de la Comunidad Andina de Naciones. En concordancia con el literal h) del artículo 31 de la ADPIC.

${ }^{11}$ Artículo 63 de la Decisión 486 de la Comunidad Andina de Naciones.

${ }^{12}$ A diferencia de las justificaciones que puede presentar el titular de la patente, quien además de estas razones puede justificar su inacción con excusas legítimas, a tenor del Artículo 61 inc. 2.

${ }^{13}$ Este artículo se refiere al derecho de petición en interés general. Pero es de anotar que el Código Contencioso administrativo vigente al momento de expedirse la Resolución 12 de 2010, fue modificado por la Ley 1437 de 2011, que regirá a partir del 2 de julio del año 2012.
} 
Si del examen de forma resulta que la solicitud no contiene tales requisitos, se efectuarán los requerimientos que sean necesarios, conforme a lo dispuesto en los Artículos 12 y 13 del Código Contencioso Administrativo (Colombia, 1984) ${ }^{14}$.

$\square$ La SIC notificará la solicitud de licencia obligatoria al titular de la patente para que dentro de los sesenta (60) días hábiles siguientes haga valer las argumentaciones y aporte las pruebas que estime pertinentes.

$\square$ Vencido el término probatorio, el expediente quedará a disposición de los intervinientes, por un término de cinco (5) días hábiles; para que de estimarlo conveniente presenten los argumentos pertinentes en respaldo de sus pretensiones.

G Finalizado el término de traslado, el expediente entra a despacho para decisión mediante resolución; en la que la Superintendencia de Industria y Comercio, concederá o negará la licencia solicitada, determinando el alcance y la extensión de la misma, especificando en particular, el período por el cual se concede, el objeto de la licencia, el monto y las condiciones de la compensación económica.

\section{b) LICENCIA POR RAZONES DE INTERÉS PÚBLICO, DE EMERGENCIA O DE SEGURIDAD NACIONAL}

Esta sería tal vez la causa más importante para el otorgamiento de licencias obligatorias, a razón de la cantidad de epidemias y enfermedades que aquejan a los países en vía de desarrollo, el alto costo de los fármacos y la imposibilidad de acceder a ellas por parte de la población. Siendo el tema de mayor impacto para los intereses generales.

De acuerdo a lo dispuesto por la Decisión 486 de la Comunidad Andina de Naciones (Comunidad Andina de Naciones, 2000), es viable esta clase de licencias, cuando:

1. Haya una declaratoria previa de razones de interés público, de emergencia, o de seguridad nacional;

2. Solo mientras estas razones permanezcan;

3. No es necesario, en este tipo de licencias, haber negociado previamente con el titular de la patente ${ }^{15}$.

\footnotetext{
${ }^{14}$ Se reitera la modificación surtida en el Código Contencioso Administrativo por la Ley 1437 de 2011, que expide un nuevo Código para el año 2012. En todo caso, los Artículos 12 y 13 que regirá hasta esa, regulan lo concerniente a:

ARTíCULO 12. - Solicitud de informaciones o documentos adicionales. Si las informaciones o documentos que proporcione el interesado al iniciar una actuación administrativa no son suficientes para decidir, se le requerirá, por una sola vez, con toda precisión y en la misma forma verbal o escrita en que haya actuado, el aporte de lo que haga falta. Este requerimiento interrumpirá los términos establecidos para que las autoridades decidan. Desde el momento en que el interesado aporte nuevos documentos o informaciones con el propósito de satisfacer el requerimiento, comenzarán otra vez a correr los términos pero, en adelante, las autoridades no podrán pedir más complementos, y decidirán con base en aquello de que dispongan.

ARTíCULO 13. -Desistimiento. Se entenderá que el peticionario ha desistido de su solicitud si hecho el requerimiento de completar los requisitos, los documentos o las informaciones de que tratan los dos artículos anteriores, no da respuesta en el término de dos (2) meses. Acto seguido se archivará el expediente, sin perjuicio de que el interesado presente posteriormente una nueva solicitud.

${ }^{15}$ Así lo establece ADPIC en el literal b) del Artículo 31.
} 
Estas causas generaban dudas acerca de qué podía considerarse como razones de interés público o de extrema urgencia que permitieran hacer uso de las licencias obligatorias. Sin embargo, la "Declaración relativa al Acuerdo sobre los ADPIC y la salud pública" reconoció la gravedad de los problemas de salud pública que afligen a muchos países en vía de desarrollo, confirmando que el Acuerdo sobre los ADPIC no impediría la adopción de medidas para proteger un interés de esta índole, ratificando que cada miembro tiene el derecho a conceder licencias obligatorias y es libre para determinar lo que constituye una emergencia nacional u otras circunstancias de extrema urgencia.

Habiendo declaratoria de la existencia de uno de estos estados, se otorgarán las licencias que se le soliciten, y el titular será notificado cuando sea razonablemente posible. Así lo dispone tanto la Decisión 486 como ADPIC.

Al igual que la licencia por falta de uso, la autoridad fijará el alcance, período, objeto condiciones y monto de la compensación; atendiendo a lo establecido por el Artículo 68 de la Decisión. La concesión de la licencia no priva al titular de seguir explotándola.

Por su parte, la Declaración del 30 de agosto de 2003 del Consejo general de la OMC (Organización Mundial de la Salud, 2003), novedosamente añadió al régimen de concesión de licencias obligatorias, entre otras cosas: el no establecer limitación a las cantidades de medicamentos que se pueden fabricar; exportar e importar al amparo de una licencia; y en el tema de la remuneración para el titular de la patente, indica que se realizará en el miembro que actúe como exportador habida cuenta del valor económico que tenga para el miembro importador el uso autorizado.

Los aspectos formales y procedimentales son:

Una vez publicada en el Diario Oficial la declaratoria de razones de interés público o las razones de emergencia o seguridad nacional, para someter a una patente a licencia obligatoria por parte de la entidad competente, la SIC comunicará, dentro de los quince (15) días hábiles siguientes a la fecha de dicha publicación, mediante aviso en la página web, lo siguiente:

a) Que las patentes señaladas en la declaratoria podrán ser licenciadas;

b) Que se recibirán solicitudes de licencias obligatorias sobre las patentes señaladas en la declaratoria;

c) El plazo en que se recibirán las solicitudes y,

d) Los términos, condiciones y requisitos especiales que deben reunir las solicitudes de la clase particular de licencia obligatoria, en razón de las causales específicas que constituyen el interés público o de emergencia o seguridad nacional.

Las solicitudes de estos tipos de licencia deben cumplir los términos, condiciones y requisitos especiales, en razón de las causales específicas para cada licencia. 
La SIC realizará un examen de forma y efectuado el estudio de la solicitud, tomará la decisión de conceder o negar la solicitud.

\section{c) LICENCIA CUANDO SE PRESENTEN PRÁCTICAS QUE AFECTEN LA LIBRE COMPETENCIA}

En general las licencias obligatorias actúan como freno o forma de evitar los abusos al derecho de propiedad que otorgan las patentes.

Por su misma naturaleza la patente genera una posición de dominio en el mercado que en no pocos casos puede tornarse abusiva. Y para corregir esa situación, la licencia obligatoria por prácticas que afecten la libre competencia resulta más que necesaria, justa.

1. Para que pueda otorgarse esta licencia, es necesario que haya una calificación previa por parte de autoridad competente de la existencia de prácticas que afectan la libre competencia, o constituyan un abuso de la posición dominante en el mercado por parte del titular de la patente;

2. Además debe aparecer que tal conducta puede superarse con el otorgamiento de la licencia obligatoria ${ }^{16}$.

No es necesario, como en caso de interés público, de emergencia o de seguridad nacional, haber intentado obtener previamente una licencia voluntaria.

Esta licencia, puede otorgarse a solicitud de parte o de oficio. En todo caso se publicará informando que tales patentes se encuentran en disposición de ser licenciadas. En la publicación deberá expresarse cuál es la conducta que ha dado origen a ello.

Para la compensación en este tipo de licencia se tendrá en cuenta la necesidad de corregir las prácticas anticompetitivas, por lo que no necesariamente ha de ser adecuada.

El procedimiento consagrado en la Resolución 12 de 2010 de la SIC (Superintendencia de Industria y Comercio, 2010), es el siguiente:

Una vez quede en firme la Resolución de la SIC que como autoridad nacional en materia de protección de la competencia profiera, calificando la necesidad de otorgar una licencia obligatoria sobre una patente, ante la existencia de prácticas que afecten la libre competencia, de conformidad con lo establecido en el Artículo 66 de la Decisión 486 de 2000 (Comunidad Andina de Naciones, 2000), comunicará, dentro de los cinco (5) días hábiles siguientes a esa fecha, mediante aviso en la página web, lo siguiente:

a) Que las patentes señaladas en la declaratoria podrán ser licenciadas;

\footnotetext{
${ }^{16}$ Así se desprende de la Circular Única de la Superintendencia de Industria y comercio.
} 
b) Que se recibirán solicitudes de licencias obligatorias sobre las patentes señaladas en la decisión expedida por la autoridad en materia de libre competencia;

c) El plazo en que se recibirán las solicitudes y,

d) Los términos, condiciones y requisitos especiales que deben reunir las solicitudes de la clase particular de licencia obligatoria, en razón de las causales específicas.

Igualmente se realizará el examen de forma, traslado, pruebas, traslado para argumentos de conclusión y decisión

Desde el momento de la presentación de una solicitud de licencia obligatoria, la Superintendencia de Industria y Comercio podrá realizar de oficio las actuaciones que sean pertinentes y solicitar la información que pueda ser de utilidad para resolver.

\section{d) LICENCIA POR DEPENDENCIA DE PATENTE}

Esta licencia es otorgada bajo los siguientes supuestos:

1. Debe ser solicitada por el titular de una patente;

2. Para la explotación de dicha patente requiera necesariamente del empleo de otra patente;

3. No haya podido acceder obtener una licencia voluntaria en condiciones comerciales razonables.

Además de esto y a lo establecido en el Artículo 68 (que es una adición en general de las licencias obligatorias), esta licencia deberá cumplir con lo siguiente:

a) La invención reivindicada en la segunda patente ha de suponer un avance técnico importante de una importancia económica considerable con respecto a la invención reivindicada en la primera patente;

b) El titular de la primera patente tendrá derecho a una licencia cruzada en condiciones razonables para explotar la invención reivindicada en la segunda patente; $y$,

c) No podrá cederse la licencia de la primera patente sin la cesión de la segunda patente.

El procedimiento y forma de solicitud para este tipo de licencias es en lo pertinente, igual al de las de falta de explotación.

Todas estas clases de licencia, como se ha señalado, deberán cumplir con las sujeciones sustanciales propias de cada una de ellas pero además con lo dispuesto por el Artículo 68 de la 
Decisión 486 de la Comunidad Andina de Naciones (Comunidad Andina de Naciones, 2000). De no cumplirse, las licencias obligatorias no surtirán efecto alguno.

\section{CONCLUSIONES}

La propiedad es un derecho fundamental en el derecho colombiano, pero que en su ejercicio y esencia misma debe cumplir una función social.

Al ser la propiedad industrial un bien, aunque mercantil, debe cumplir las finalidades propias de todo bien, al igual que el derecho fundamental de libertad de empresa. Por ello no es desentonado que el ejercicio de las patentes sufra recortes en su ejercicio cuando se presenten ciertas circunstancias que así lo ameriten.

Conforme al marco normativo que regula la propiedad industrial en el ordenamiento colombiano, que está basado en la Decisión 486 de 2000 de la Comunidad Andina de Naciones (Comunidad Andina de Naciones, 2000), las patentes pueden ser transferidas por su titular mediante actos entre vivos o por causa de muerte. En consecuencia pueden otorgarse licencias libremente por quien ostenta el derecho, para que otros la exploten.

El titular de las patentes no solo adquiere derechos, pues se derivan también obligaciones, debiendo entonces explotar su invención. Al no cumplir con tal obligación, esto permite que terceros interesados puedan elevar solicitudes de licencias obligatorias por esta desidia.

Sumada a la hipótesis de falta de explotación, pueden otorgarse igualmente licencias obligatorias por las autoridades nacionales, por razones de interés público, de emergencia o de seguridad nacional. También es viable cuando se presenten prácticas que afecten la libre competencia o abuso de la posición dominante.

Como último supuesto está habilitada la solicitud de este tipo de licencias obligatorias en el caso de que un titular de una patente requiera necesariamente el empleo de otra patente y no haya podido adquirir una licencia voluntaria en condiciones comerciales razonables. 


\section{REFERENCIAS BIBLIOGRÁFICAS}

ASAMBLEA NACIONAL CONSTITUYENTE. (1991) “Constitución Política de Colombia”. Bogotá DC, Colombia.

COLOMBIA. (1971) Decreto 410 de 1971. "Código de Comercio". Bogotá DC, Colombia: Congreso de la República.

COLOMBIA. (1984) “Código Contencioso Administrativo”. Bogotá DC: Diario Oficial.

COMITÉ DE NEGOCIACIONES COMERCIALES. (15 de abril de 1994) Acuerdo de la Ronda Uruguay. "Declaración de Marrakech". Marruecos: Comité de Negociaciones Comerciales.

COMITÉ DE NEGOCIACIONES COMERCIALES. (15 de abril de 1994) Acuerdo de la Ronda Uruguay. "Declaración de Marrakech-Anexo 1C". Marruecos: Comité de Negociaciones Comerciales.

COMUNIDAD ANDINA DE NACIONES. (2000) “Decisión 486". Lima, Perú: Secretaría General de la Comunidad Andina.

CORREA, C., \& BERGEL, S. (1996) “Patentes y competencia”. Buenos Aires: Rubinzal Culzoni.

ORGANIZACIÓN MUNDIAL DE LA SALUD. (2003) “Acuerdo del 30 de agosto de 2003". Ginebra, Siuza: Organización Mundial de la Salud.

SUPERINTENDENCIA DE INDUSTRIA Y COMERCIO. (2010) “Resolución 12 de 2010”. Bogotá DC, Colombia: Ministerio de Comercio, Industria y Turismo. 